\title{
Doxorubicin-induced oxidative and nitrosative stress: Mitochondrial connexin 43 is at the crossroads
}

\author{
MICHELA PECORARO ${ }^{1}$, BARBARA PALA ${ }^{2}$, MARIA CARMELA DI MARCANTONIO $^{2}$, RAFFAELLA MURARO $^{2}$, \\ STEFANIA MARZOCCO $^{1}$, ALDO PINTO ${ }^{1}$, GABRIELLA MINCIONE $^{2}$ and ADA POPOLO ${ }^{1}$ \\ ${ }^{1}$ Department of Pharmacy, University of Salerno, I-84084 Fisciano (SA); ${ }^{2}$ Department of Medical, \\ Oral and Biotechnological Sciences, 'G. d'Annunzio' University of Chieti-Pescara, I-66100 Chieti, Italy
}

Received December 18, 2019; Accepted June 16, 2020

DOI: $10.3892 /$ ijmm.2020.4669

\begin{abstract}
Oxidative stress is widely accepted as a key factor of doxorubicin (Doxo)-induced cardiotoxicity. There is evidence to indicate that nitrosative stress is involved in this process, and that Doxo interacts by amplifying cell damage. Mitochondrial connexin 43 (mitoCx43) can confer cardioprotective effects through the reduction of mitochondrial reactive oxygen species production during Doxo-induced cardiotoxicity. The present study aimed to evaluate the involvement of mitoCx43 in Doxo-induced nitrosative stress. Rat H9c2 cardiomyoblasts were treated with Doxo in the absence or presence of radicicol, an inhibitor of Hsp90, the molecular chaperone involved in Cx43 translocation to the mitochondria that underlies its role in cardioprotection. FACS analysis and RT-qPCR revealed that Doxo increased superoxide dismutase, and catalase gene and protein expression. As shown by hypodiploid nuclei and confirmed by western blot analysis, Doxo increased caspase 9 expression and reduced procaspase 3 levels, which induced cell death. Moreover, a significant increase in the activation of the NF- $\kappa \mathrm{B}$ signaling pathway was observed. It is well known that the increased expression of inducible nitric oxide synthase results in nitric oxide overproduction, which then rapidly reacts with hydrogen peroxide or superoxide generated by the mitochondria, to form highly reactive and harmful peroxynitrite, which ultimately induces nitrotyrosine formation. Herein, these interactions were confirmed and increased effects were observed in the presence of radicicol. On the whole, the data of the present study indicate that an interplay between
\end{abstract}

Correspondence to: Dr Ada Popolo, Department of Pharmacy, University of Salerno, via Giovanni Paolo II 132, I-84084 Fisciano (SA), Italy

E-mail: apopolo@unisa.it

Dr Gabriella Mincione, Department of Medical, Oral and Biotechnological Sciences, 'G. d'Annunzio' University of Chieti-Pescara, via dei Vestini 31, I-66100 Chieti, Italy

E-mail: gabriella.mincione@unich.it

Key words: cardiotoxicity, connexin 43, oxidative stress, nitrosative stress, doxorubicin oxidative and nitrosative stress is involved in Doxo-induced cardiotoxicity, and that both aspects are responsible for the induction of apoptosis. Furthermore, it is demonstrated that the mechanisms that further increase mitochondrial superoxide generation (e.g., the inhibition of $\mathrm{Cx} 43$ translocation into the mitochondria) significantly accelerate the occurrence of cell death.

\section{Introduction}

Connexin $43(\mathrm{Cx} 43)$ is a major gap-junction protein that mediates intercellular communication by promoting the passage of small molecules and ions (1). In cardiomyocytes, Cx43 regulates electrical coupling and synchronous contraction (2). Alterations to $\mathrm{Cx} 43$ expression and distribution have been reported for several cardiopathological conditions, such as heart failure. The decreased expression and/or heterogeneous distribution of $\mathrm{Cx} 43$ has been demonstrated in the myocardium of patients with hypertrophic cardiomyopathies, dilated cardiomyopathies, ischemic cardiomyopathies and clinical congestive heart failure (3).

In addition to the well-known role of $\mathrm{Cx} 43$ in the cell membrane, in recent years, ample attention has been paid to the mitochondrial isoform of $\mathrm{Cx} 43$ (mitoCx43). It is well known that $\mathrm{Cx} 43$ translocates to the mitochondrial membrane through a mechanism that involves Hsp90 as its chaperone and Tom 20 as a mitochondrial translocase (4). Previous studies have reported that mitoCx43 plays an important role in the balance of reactive oxygen species (ROS) for redox signalling $(5,6)$. MitoCx43 is also involved in cardioprotection, as it has been demonstrated that it is overexpressed in ischemic pre-conditioning (7), as well as in other forms of cardioprotection, through the control of the initiation of apoptosis (8). The authors have previously demonstrated an increase in mitoCx43 expression in $\mathrm{H} 9 \mathrm{c} 2$ cells (9) and in hearts of mice treated with doxorubicin (Doxo) (10). This overexpression is an adaptive response that can be activated to counteract the intracellular $\mathrm{Ca}^{2+}$ overload, ROS production and the propagation of apoptotic signals induced by Doxo. Indeed, Doxo is widely used as a chemotherapeutic agent, although its clinical use is hampered by its potential to elicit cardiotoxicity. The onset of Doxo-induced cardiomyopathy can occur without warning, and this condition can be rapidly abrogated; moreover, 
oxidative stress has been recognized as the main cause in this process (11). A variety of mechanisms are involved in Doxo-induced cardiotoxicity, such as oxidative stress, the dysregulation of calcium homeostasis and inflammation (12), and these all converge on the mitochondria (13). The induction of free radical stress by Doxo results in mitochondrial membrane depolarization and the release of cytochrome $c$ into the cytoplasm, which can then trigger apoptosis (9).

In addition to oxidative stress, there is evidence to indicate that nitrosative stress is involved in Doxo-induced cardiotoxicity, as increases in reactive nitrogen species (such as peroxynitrite) have been reported (14). Peroxynitrite is a potent, reactive and cytotoxic free radical that is formed through a reaction that involves nitric oxide (NO) and the superoxide anion $\left(\mathrm{O}_{2}^{-}\right)$. In Doxo-treated cardiomyocytes, large amounts of NO are produced by the inducible isoform of NO synthase (iNOS), a downstream effector of the nuclear transcription factor NF- $\mathrm{B}$ (15). Both of these oxidative species (i.e., NO, $\mathrm{O}_{2}^{-}$), are mediators of inflammatory conditions.

ROS are oxygen-based chemical species that show high reactivity. These include free radicals, such as $\mathrm{OH}^{-}$and $\mathrm{O}_{2}^{-}$, and non-radicals that can generate free radicals, such as hydrogen peroxide $\left(\mathrm{H}_{2} \mathrm{O}_{2}\right) . \mathrm{O}_{2}^{-}$is a primary radical that can lead to the formation of other types of ROS, such as $\mathrm{H}_{2} \mathrm{O}_{2}$ and $\mathrm{OH}^{-}$. $\mathrm{OH}^{-}$ is also generated by the reduction of $\mathrm{H}_{2} \mathrm{O}_{2}$ in the presence of endogenous iron, through the Fenton reaction. In addition, $\mathrm{OH}^{-}$can arise from electron exchange between $\mathrm{O}_{2}{ }^{-}$and $\mathrm{H}_{2} \mathrm{O}_{2}$, via the Harber-Weiss reaction. Furthermore, when both $\mathrm{O}_{2}$ and NO are synthesized within a few cell diameters, they can combine spontaneously to form peroxynitrite $\left(\mathrm{ONOO}^{-}\right)$, which is a potent, reactive and cytotoxic free radical $(16,17)$.

Three isoforms of NOS have been defined: Endothelial NOS (eNOS or NOS3), neuronal NOS (nNOS or NOS1) and inducible NOS (iNOS or NOS2). NOS1 and NOS3 are constitutive enzymes that are controlled by intracellular $\mathrm{Ca}^{2+} /$ calmodulin; NOS2 is inducible at the level of gene transcription, and it is $\mathrm{Ca}^{2+}$-independent and expressed by macrophages and other tissues in response to (pro)inflammatory mediators, such as $\mathrm{NF}-\kappa \mathrm{B}$, which was observed to be increased in the present study.

There is ample evidence to indicate that oxidative stress and inflammation are implicated in the pathogenesis of congestive heart failure. Indeed, Doxo itself is a potent activator of $N F-\kappa B(18)$, the main nuclear transcription factor that is involved in inflammation. A sustained inflammatory/oxidative environment leads to damage to cells, which can then remain in a vicious circle of impaired pathways $(17,19,20)$. Furthermore, an increase in NO production in the myocardium in itself can result in the nitration of actin and other cytoskeletal proteins, thus altering their structures and resulting in harmful effects on the contractile function of myofilaments (21).

NO is necessary for the regulation of cardiac function during normal cardiac physiology, including for coronary vasodilatation, the inhibition of platelet and neutrophil adhesion and activation, and the modulation of cardiac contractile function. NO also plays a protective role against the ischemic and/or failing heart. This protective role is mediated through several mechanisms, which include the stimulation of soluble guanylyl cyclase. This leads to a decrease in the concentration of intracellular $\mathrm{Ca}^{2+}$ and inhibition of oxidative stress.
Therefore, $\mathrm{O}_{2}^{-}$can exert cytotoxic effects not only directly due to $\mathrm{O}_{2}^{-}$itself, but also mediated through the inactivation of cytoprotective $\mathrm{NO}$ and the formation of the highly reactive oxidant $\mathrm{ONOO}^{-}$, which is produced following interactions between $\mathrm{NO}$ and $\mathrm{O}_{2}^{-}$.

It was hypothesized that as a regulator of mitochondrial ROS production, $\mathrm{mCx} 43$ is also involved in the regulation of antioxidant enzymes and in the production of downstream effectors of oxidative/nitrosative signaling pathways. For this purpose, a well-designed in-vitro model of Doxo-induced cardiotoxicity with embryonic rat heart cardiomyoblasts (H9c2 cells) was used, as these cells are generally accepted as a good model to study the mechanisms of cellular and cardiac protection (9). To achieve this goal, the H9c2 cells were treated with Doxo and radicicol, a well-established Hsp90 inhibitor (22) that, as previously reported, was used herein to inhibit the translocation of $\mathrm{Cx} 43$ to the mitochondria (9). The present study provides evidence that Doxo-induced cardiotoxicity occurs not only via caspase-mediated apoptosis, but also through the NF- $\mathrm{NB}$ signaling pathway. Oxidative and nitrosative stress-induced damage is amplified in $\mathrm{H} 9 \mathrm{c} 2$ cells in which the translocation of $\mathrm{Cx} 43$ to the mitochondrion is inhibited, which thus confirms the cardioprotective effects of mitoCx43 (Fig. S1).

\section{Materials and methods}

Materials and cell culture. Doxo was obtained from Baxter Manufacturing Spa. Radicicol and L-NAME were from Sigma-Aldrich; Merck KGaA. The H9c2 embryonic rat heart cardiomyocyte-derived cell line was purchased from the American Tissue Culture Collection (ATCC), with mycoplasma testing carried out. The H9c2 cells were grown to confluence in Dulbecco's modified Eagle's medium (DMEM; Microgem) with $10 \%$ fetal bovine serum (FBS; Microgem) and antibiotics (25 U/ml penicillin; $25 \mathrm{U} / \mathrm{ml}$ streptomycin) under an atmosphere of $95 \%$ air $/ 5 \% \mathrm{CO}_{2}$ at $37^{\circ} \mathrm{C}$.

Experimental protocol. The H9c2 cells were treated with $1 \mu \mathrm{M}$ Doxo for 3or $6 \mathrm{~h}$ in DMEM, 10\% FBS. MitoCx43 translocation was inhibited with $1 \mu \mathrm{M}$ radicicol, an Hsp90 inhibitor. Radicicol was administered $30 \mathrm{~min}$ prior to the Doxo treatments.

Cell morphology. The H9c2 cells were seeded on glass coverslips, and after $24 \mathrm{~h}$ they were treated with Doxo and radicicol according to the protocol described above. At the indicated time points, the $\mathrm{H} 9 \mathrm{c} 2$ cells were fixed with $70 \%$ ethanol and stained with $1 \%$ toluidine blue solution (TAAB Laboratories Equipment Ltd.) for $15 \mathrm{~min}$ at room temperature. Images of approximately 50 random fields of view at a magnification of x20 were obtained using a light microscope (Axioskop 40; Carl Zeiss) equipped with a videocamera (Coolsnap; Photometrics). The images were analyzed using Axio Vision software, SE64.

Total RNA isolation and RT-qPCR analysis. The H9c2 cells were seeded at a density of $7.0 \times 10^{5}$ cells/well into $100-\mathrm{mm}$ culture dishes (Corning, Inc.) and treated as described above. Total RNA was extracted using EuroGold TriFast (EuroClone S.p.A.), according to the manufacturer instructions. RNA 
Table I. Nucleotide base sequences of primers designed for the RT-qPCR assays.

\begin{tabular}{lll}
\hline Genes & \multicolumn{1}{c}{ Forward $\left(5^{\prime} \rightarrow 3^{\prime}\right)$} & \multicolumn{1}{c}{ Reverse $\left(5^{\prime} \rightarrow 3^{\prime}\right)$} \\
\hline$A C T B$ & GGGAAATCGTGCGTGACATT & TACCCAGGAAGGAAGGCTGG \\
$C A T$ & ACAACTCCCAGAAGCCTAAGAATG & GGCTTGTGCCCTGCTTCATG \\
$M n S O S$ & CAAGGTCTACGTTCAAGACAT & AAAGTGGTAGCCACATCCCG \\
$H P R T 1$ & ATTAACGCGCAGATCATGCA & GGCTGAAGAGCAACCTGAGTT \\
& CAGTCCCAGCGTCGTGATTAGT & ATCCAGCAGGTCAG
\end{tabular}

$A C T B$, actin beta; $C A T$, catalase; NOS2, nitric oxide synthase 2; MnSOD, manganese superoxide dismutase; HPRT1, hypoxanthine phosphoribosyltransferase 1 .

concentrations and quality were determined by absorbance measurements using a UV-Vis spectrophotometer (NanoDrop 2000; Thermo Fisher Scientific, Inc.). The ratios of the absorbance at 260 to $280 \mathrm{~nm}$ and at 260 to $230 \mathrm{~nm}$ were used to determine the purity of the total RNA samples, which were then stored at $-70^{\circ} \mathrm{C}$. Reverse transcription reactions were carried out using reverse transcription-quantitative PCR (RT-qPCR; GoTaq 2-Step system; Promega Corp.). The cDNAs were synthesized starting from $1 \mu \mathrm{g}$ purified total RNA, according to the manufacturer instructions. The expression level of the catalase $(C A T)$, manganese superoxide dismutase $(M n S O D)$ and $i N O S$ genes were evaluated using SYBR-Green RT-qPCR analysis (StepOne 2.0; Applied Biosystems; Thermo Fisher Scientific, Inc.). The cycling conditions were performed as follows: $10 \mathrm{~min}$ at $95^{\circ} \mathrm{C}$ and 40 cycles of $15 \mathrm{sec}$ at $95^{\circ} \mathrm{C}$ followed by $1 \mathrm{~min}$ at $60^{\circ} \mathrm{C}$ and final elongation of $15 \mathrm{sec}$ at $95^{\circ} \mathrm{C}$. The data were analyzed using the comparative $\mathrm{Cq}$ method, and are illustrated graphically as $2^{-\Delta \Delta \mathrm{Cq}} \pm$ standard deviation (SD) (23). Targets and reference genes were amplified separately in triplicate, in $10 \mu \mathrm{l}$ containing $1 \mu \mathrm{l}$ template cDNA, $0.2 \mu \mathrm{l}$ primers mixture, and $5 \mu \mathrm{l}$ enzyme mix (GoTaq 2-Step RT-qPCR system; Promega Corp.). For the RT-qPCR assays, the primers were designed using Allele ID (Premier Biosoft International) and IDT SciTools, Inc. (TEMA Ricerca), and are presented in Table I. The products of real-time PCR were electrophoresed on a 1,5\% agarose gel with ethidium bromide and then captured using the Gel Doc EZ Imaging System with Image Lab software 5.0 (Bio-Rad Laboratories, Inc.).

Measurement of mitochondrial superoxide with MitoSOX red. Mitochondrial superoxide formation was evaluated using MitoSOX red (Molecular Probes, Invitrogen; Thermo Fisher Scientific, Inc.). Briefly, the H9c2 cells were plated at $4.0 \times 10^{5}$ cells/well in 6 -well tissue culture plates, and were treated as described above. Following the indicated incubations, $2.5 \mu \mathrm{M}$ MitoSOX red was added for $15 \mathrm{~min}$ at $37^{\circ} \mathrm{C}$. MitoSOX red is a fluorogenic dye for the highly selective detection of superoxide in the mitochondria of living cells and, once targeted to the mitochondria, it is oxidized by superoxide and emits red fluorescence. MitoSOX red is readily oxidized by superoxide, but not by other ROS-generating systems. Cell fluorescence was measured using fluorescence-activated cell sorting (FACS, BD Biosciences) by counting 10,000 events/min, and analyzed using CellQuest software, (version 5.2.1). These data are reported as percentages of positive cells, as referred at the 'gate', which was the sequential identification and refinement of the cellular population using MitoSOX red as the marker that was visualized by fluorescence as a unique emission spectrum.

Measurement of mitochondrial membrane depolarization. Mitochondrial membrane depolarization was measured using FACS scans and the fluorescent dye tetramethylrhodamine methyl ester (TMRE). Due to its positive charge, TMRE readily accumulates in active mitochondria in inverse proportion to $\Delta \psi \mathrm{m}$ according to the Nernst equation. The H9c2 cells were seeded at $4.0 \times 10^{5}$ cells/well in 6 -well tissue culture plates, and treated as described above. The H9c2 cells were then collected, washed twice with phosphate-buffered saline (PBS), and incubated in PBS containing $5 \mathrm{nM} \mathrm{TMRE}$ at $37^{\circ} \mathrm{C}$. After $30 \mathrm{~min}$, cell fluorescence was evaluated using FACS, and analyzed using CellQuest software, version 5.2.1.

Mitochondrial protein extraction and western blot analysis for mitochondrial $C x 43$. The $\mathrm{H} 9 \mathrm{c} 2$ cells were seeded at $1.0 \times 10^{6}$ cells/well in 100-mm culture dishes (Corning, Inc.), and treated as described above. Mitochondrial protein extraction was carried out as previously described (9). Briefly, the $\mathrm{H} 9 \mathrm{c} 2$ cells were lysed in buffer A $(250 \mathrm{mM}$ sucrose, $20 \mathrm{mM}$ $\mathrm{K}^{+}$Hepes, pH 7.5, $10 \mathrm{mM} \mathrm{KCl}, 1.5 \mathrm{mM} \mathrm{MgCl}_{2}, 1 \mathrm{mM}$ EDTA, $1 \mathrm{mM}$ EGTA, protease inhibitors, $50 \mathrm{mM} \mathrm{NaF}, 0.2 \mathrm{mM} \mathrm{Na}_{3} \mathrm{VO}$, $1 \mathrm{mM}$ phenylmethylsulfonyl fluoride, $1 \mathrm{mM}$ dithiothreitol and $0.025 \%$ digitonin). The $\mathrm{H} 9 \mathrm{c} 2$ cells were then centrifuged at $16,000 \mathrm{xg}$ for $2 \mathrm{~min}$ at $4^{\circ} \mathrm{C}$. The supernatants were discarded, and the pellets were resuspended in lysis buffer B [150 mM $\mathrm{NaCl}, 0.1 \%$ Triton-X, $0.5 \%$ sodium deuteroxide, $1 \%$ sodium dodecyl sulfate (SDS), $50 \mathrm{mM}$ Tris/ $\mathrm{HCl}, \mathrm{pH} 7.4$; all from Sigma-Aldrich; Merck KGaA], to obtain the mitochondrial proteins. Protein concentrations were determined using protein assays (Bio-Rad Laboratories, Inc.). Equal amounts of protein were loaded onto an acrylamide gel (50 $\mu \mathrm{g}$ protein/lane), and separated by $10 \%$ SDS-PAGE under denaturing conditions. The blots were incubated overnight at $4^{\circ} \mathrm{C}$ with the primary antibodies as anti-Cx43 (1:8,000, cat. no. 610062; BD Transduction Laboratories) or anti-TOM20, used as a loading control, (1:250, cat. no. sc-17764; Santa Cruz Biotechnology, Inc.). Following incubation with the primary antibodies and washing in PBS/0.1\% Tween, the appropriate secondary antibodies were added for $1 \mathrm{~h}$ at room temperature, as anti-rabbit or anti-mouse (each diluted 1:4,000, rabbit conjugate horseradish 
peroxidase, cat. no. GtxRb-003-DHRPX and mouse conjugate horseradish peroxidase, cat. no. GtxMu-003-DHRPX; Microtech). Immunoreactive protein bands were detected by chemiluminescence using enhanced chemiluminescence reagents and blot imaging (LAS 4000; GE Healthcare); densitometry was performed using ImageJ, 1.52t (Wayne Rasband) To determine the purity of mitochondrial protein extraction, western blot analysis was performed for proteins expressed only in the mitochondria (Ox-Phos Complex II; Abcam) without including proteins expressed in other cellular compartments (e.g., $\mathrm{Na}^{+} / \mathrm{K}^{+}$ATPase; Abcam) (24).

Total protein extraction and western blot analysis. The $\mathrm{H} 9 \mathrm{c} 2$ cells were seeded at $7.0 \times 10^{5}$ cells/well in $100-\mathrm{mm}$ culture dishes (Corning, Inc.), and treated as described above. Total protein was extracted from the cells by freeze/thawing in lysis buffer (50 mM NaF, $150 \mathrm{mM} \mathrm{NaCl}, 50 \mathrm{mM}$ Tris/HCl, pH 7.4, $1 \%$ Nonidet P40, $1 \mathrm{mM}$ EDTA, $0.2 \mathrm{mM} \mathrm{Na}_{3} \mathrm{VO}_{4}, 1 \mathrm{mM}$ phenylmethylsulfonyl fluoride and protease inhibitors; all from Sigma-Aldrich; Merck KGaA). Protein concentrations were determined using protein assays (Bio-Rad Laboratories, Inc.). Total cell extracts containing equal amounts of protein $(50 \mu \mathrm{g}$ protein/lane) were separated on $10 \%$ SDS-polyacrylamide gels under denaturing conditions, and transferred to nitrocellulose membranes (Amersham, GE Healthcare) using a semi-dry transfer apparatus (Bio-Rad Laboratories, Inc.). The blots were blocked with $5 \%$ non-fat dry milk powder in PBS for $1 \mathrm{~h}$ at room temperature. The membranes were then incubated for $1 \mathrm{~h}$ at $4^{\circ} \mathrm{C}$ with the primary antibodies, as anti-procaspase 3 , anti-caspase 9, anti-iKK $\alpha$ (all diluted 1:200; cat. nos. sc-56052, sc-76548, sc-7606, Santa Cruz Biotechnology, Inc.), and anti-iNOS (diluted 1:8,000; cat. no. sc-7271, Santa Cruz Biotechnology, Inc.). Gapdh (diluted 1:1,000; cat. no. sc-32233, Santa Cruz Biotechnology, Inc.) was used as the loading control. After washing in PBS/ $0.1 \%$ Tween, the appropriate secondary antibodies were added for $1 \mathrm{~h}$ at room temperature, as anti-rabbit (diluted 1:5,000; rabbit conjugate horseradish peroxidase, cat. no. GtxRb-003-DHRPX; Microtech) or anti-mouse (diluted 1:4,000, mouse conjugate horseradish peroxidase, cat. no. GtxMu-033-DHRPX; Microtech). The immunoreactive protein bands were detected using enhanced chemiluminescence immunoassay reagents and blot imaging (LAS 4000; GE Healthcare), densitometry was performed using ImageJ, 1.52t (Wayne Rasband).

Flow cytometric analysis. The H9c2 cells were cultured at $4.5 \times 10^{5}$ cells/well in 6 -well plates and allowed to grow for $24 \mathrm{~h}$. They were then treated as described above to determine the CAT, MnSOD, p-IKB and nitrotyrosine levels. The H9c2 cells were collected using a scraper, treated with fixing buffer (4\% formaldehyde, $0.1 \% \mathrm{NaN}_{3}, 2 \% \mathrm{FBS}$, in PBS) for $20 \mathrm{~min}$, and then permeabilized using a fixation and permeabilization buffer (fixing buffer containing $0.1 \%$ Triton X) for $30 \mathrm{~min}$. Subsequently, these cells were incubated with the anti-CAT (diluted 1:250; cat. no. sc-271803; Santa Cruz Biotechnology, Inc.), anti-MnSOD (diluted 1:250; cat. no. sc-137254; Santa Cruz Biotechnology, Inc.), anti-p-IKB and anti-nitrotyrosine antibodies (both diluted 1:250; cat. no. sc-137254 and sc-32757 respectively; Santa Cruz Biotechnologies) for $1 \mathrm{~h}$ at $4^{\circ} \mathrm{C}$, as required, followed by the respective anti-rabbit or anti-mouse
FITC antibodies as the secondary antibodies (diluted both 1:5,000; cat. nos. A120-208F and A90-146F, respectively; Bethyl Laboratories), for $1 \mathrm{~h}$ at $4^{\circ} \mathrm{C}$. The cells were collected and analyzed by FACS (FACSscan; BD Biosciences) and the data obtained were processed using the CellQuest software, version 5.2.1. These data are shown as percentages of positive cells.

Analysis of apoptosis. The $\mathrm{H} 9 \mathrm{c} 2$ cells were plated at $4.5 \times 10^{5}$ cells/well in 6-well plates and allowed to grow for $24 \mathrm{~h}$, and then treated as described above. In order to estimate specifically the pro-apoptotic effect of iNOS and its products in Doxo-treated cells, in other experiments, the H9c2 cells were treated with L-NAME $(1 \mu \mathrm{M})$, a specific iNOS inhibitor, administered $30 \mathrm{~min}$ prior to Doxo treatment. The $\mathrm{H} 9 \mathrm{c} 2$ cells were washed twice with PBS, and incubated in $500 \mu \mathrm{l} 0.1 \%$ Triton X-100, $0.1 \%$ sodium citrate, and $50 \mu \mathrm{g} / \mathrm{ml}$ propidium iodide, at $4^{\circ} \mathrm{C}$ for $30 \mathrm{~min}$ in the dark. The propidium-iodide-stained cells were analyzed by FACS, using CellQuest software, version 5.2.1. These data are expressed as the percentages of cells in the hypodiploid region.

Measurement of nitrite/nitrate (NOx) concentrations. NOx concentrations provide a surrogate marker for NO generation, and this was measured for the cell medium of the H9c2 cells, as previously described (25). The cell medium was incubated with $0.1 \mathrm{U} / \mathrm{ml}$ nitrate reductase, $1 \mathrm{mM}$ NADPH, and $50 \mu \mathrm{M}$ flavin adenine dinucleotide, at $37^{\circ} \mathrm{C}$. After $15 \mathrm{~min}$, the samples were incubated with $100 \mathrm{U} / \mathrm{ml}$ lactate dehydrogenase and $10 \mathrm{mM}$ sodium pyruvate, for $5 \mathrm{~min}$. The total NOx concentrations in the samples were measured using the Griess reaction, with the addition of $100 \mu \mathrm{l}$ Griess reagent ( $0.1 \%$ naphthyl ethylenediamide dihydrochloride in $\mathrm{H}_{2} \mathrm{O}, 1 \%$ sulfanilamide in $5 \%$ conc. $\left.\mathrm{H}_{2} \mathrm{PO}_{4} ; 1: 1\right)$ to $100 \mu \mathrm{l}$ samples, carried out in triplicate. The optical densities at $550 \mathrm{~nm}\left(\mathrm{OD}_{550}\right)$ were measured in a microplate reader (Titertek; Dasit). Total NOx concentrations $(\mu \mathrm{m})$ were calculated from the standard curve with sodium nitrate.

Statistical analysis. The data are presented as the means \pm standard error of the mean (SEM) for at least 3 independent experiments, with each performed in duplicate. The RT-qPCR data are presented as the means \pm SD for at least 3 independent experiments, each performed in triplicate. Statistical analysis was performed using one-way ANOVA, with multiple comparisons using Bonferroni's tests. $\mathrm{P}<0.05$ was considered to indicate a statistically significant difference.

\section{Results}

Inhibition of Cx43 translocation to the mitochondria alters H9c2 cell morphology. Morphological modifications of the $\mathrm{H} 9 \mathrm{c} 2$ cells treated with Doxo alone, with radicicol alone, or both in combination were evaluated using toluidine blue staining. As depicted in Fig. 1, the untreated control cells exhibited a characteristic spindle shape, with the nuclei clearly visible as round and central. There were also a number of nucleoli and an abundant cytoplasm component at both 3 and $6 \mathrm{~h}$ of incubation. Treatment with radicicol alone, which inhibits $\mathrm{Cx} 43$ translocation to the mitochondria, did not alter the morphology of these cells at 3 or $6 \mathrm{~h}$ of treatment. For the 
$3 \mathrm{~h}$

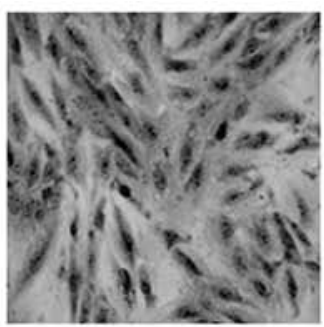

$\mathrm{h}$

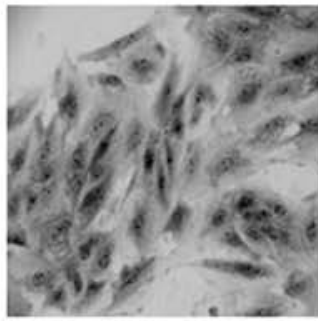

Doxo $(1 \mu \mathrm{M})$

$\operatorname{Rad}(1 \mu \mathrm{M})$
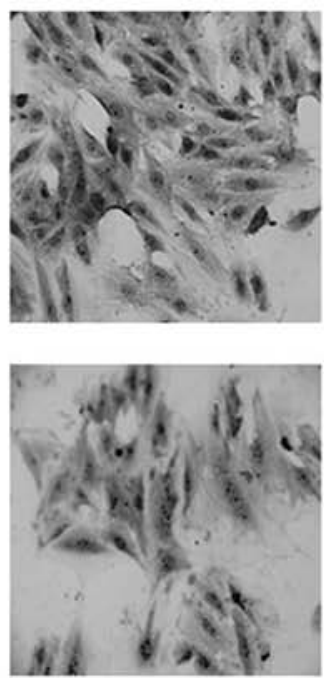

$-$
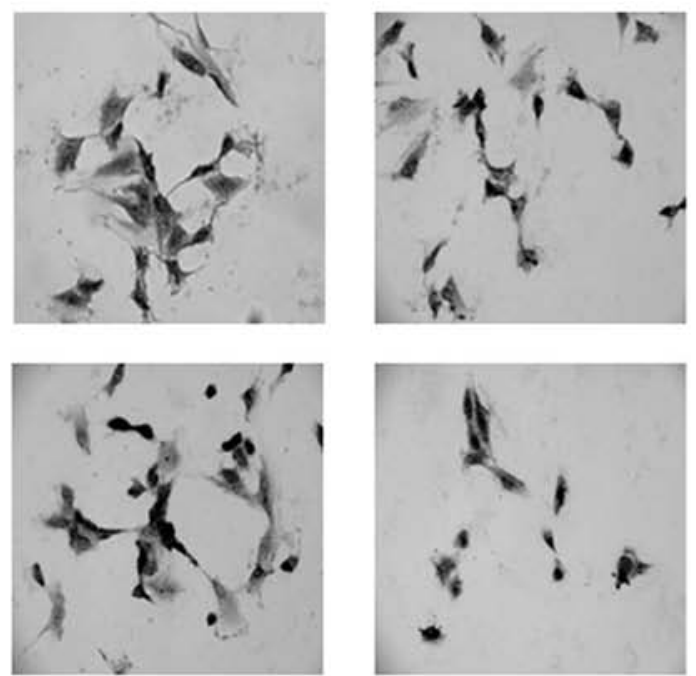

$+$

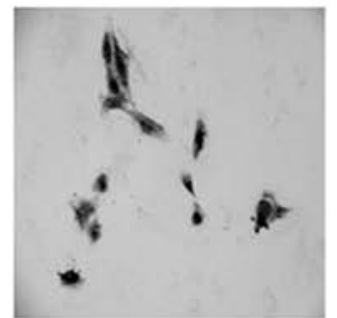

$+$

Figure 1. Effects of treatments with Doxo alone and in combination with radicicol on H9c2 cell morphology. Doxo (1 $\mu \mathrm{M})$ was administered for 3 and $6 \mathrm{~h}$, and where indicated, radicicol $(1 \mu \mathrm{M})$ was administered $30 \mathrm{~min}$ before Doxo. The $\mathrm{H} 9 \mathrm{c} 2$ cells were treated with $1 \%$ toluidine blue, a basophilic dye, to highlight their morphology, and observed under light microscopy (magnification, x20), with representative images shown. Doxo, doxorubicin; Rad, radicicol.

H9c2 cells treated with Doxo for $3 \mathrm{~h}$, the nuclei acquired an atypical, wrinkled appearance, and the cytoplasm component appeared reduced. These cells lost their cylindrical shape, and acquired an irregular shape. Moreover, following $6 \mathrm{~h}$ of Doxo treatment, nuclear and cytoplasmic involution changes were observed. Indeed, the untreated control cells were cylindrical, in contact, with roundish nuclei and evident nucleoli and abundant cytoplasm component. The treated cells, instead, exhibited a thin form, and the nuclei exhibited atypical and wrinkled aspects. Radicicol pre-treatment increased these Doxo-induced morphological changes at both 3 and $6 \mathrm{~h}$ of treatment.

Inhibition of Cx43 translocation to the mitochondria increases the Doxo effects on ROS signaling and cell death. The administration of $1 \mu \mathrm{M}$ Doxo for 3 and $6 \mathrm{~h}$ induced an increase in mitochondrial Cx43 expression, which was inhibited in the radicicol pre-treated cells (Fig. 2A). The inhibition of $\mathrm{Cx} 43$ translocation to the mitochondria was increased significantly under Doxo-induced mitochondrial ROS production and mitochondrial membrane depolarization $(\mathrm{P}<0.05$; Fig. $2 \mathrm{~B}$ and $\mathrm{C}$ ). In particular, ROS formation was determined as the mitochondrial superoxide formation with MitoSOX red, which once targeted to the mitochondria, was oxidized by superoxide and exhibited red fluorescence that was proportional to the amount of enzyme present (Fig. 2B). Mitochondrial membrane depolarization was measured using FACSscan with the fluorescent dye, TMRE. Due to its relative negative charge, TMRE is normally stored in active mitochondria, whereas mitochondria with a decreased membrane potential, and depolarized or inactive mitochondria, fail to sequester TMRE (Fig. 2C). Aerobic organisms have developed efficient defense systems of enzymatic and non-enzymatic antioxidants to ameliorate and cope with injury from oxidative damage and to maintain redox homeostasis, such as MnSOD and catalase (26). In the present study, to evaluate the effects of Doxo administration on
MnSOD and catalase, the H9c2 cells were treated as described above, and MnSOD and catalase gene and protein expression were evaluated by RT-qPCR and cytofluorimetric techniques, respectively.

The enzyme MnSOD belongs to the class of oxidoreductases, and it catalyzes the dismutation of superoxide anion into $\mathrm{H}_{2} \mathrm{O}_{2}$ and molecular oxygen, according to the following reaction: $2 \mathrm{O}_{2}^{-}+2 \mathrm{H}^{+} \leftrightarrow \mathrm{O}_{2}+\mathrm{H}_{2} \mathrm{O}_{2}$. Following treatment with $1 \mu \mathrm{M}$ Doxo for $3 \mathrm{~h}$, a small, and non-significant increase in $M n S O D$ expression was induced, which was not observed after $6 \mathrm{~h}$ of treatment (Fig. 3A). The cytofluorimetric analysis revealed that Doxo treatment significantly increased MnSOD expression $(\mathrm{P}<0.05$; Fig. 3B), after $6 \mathrm{~h}$ of treatment. Furthermore, in the $\mathrm{H} 9 \mathrm{c} 2$ cells pre-treated with radicicol, at both experimental times, MnSOD expression was higher than that in the cells treated with Doxo alone, as well as showing a significant increase compared to the untreated control cells $(\mathrm{P}<0.05$; Fig. 3B).

In the H9c2 cells treated with Doxo and radicicol, an increase in $C A T$ expression was observed after $3 \mathrm{~h}$, and, in particular, a significant additive effect $(\mathrm{P}<0.05)$ was observed following co-treatment for $3 \mathrm{~h}$. On the contrary, following co-treatment for $6 \mathrm{~h}, C A T$ expression was significantly downregulated ( $\mathrm{P}<0.005$; Fig. $4 \mathrm{~A})$. Agarose gel electrophoresis was used to monitor the PCR products, which confirmed the data obtained (Fig. 4B). The results of FACS analysis supported the RT-qPCR data, with a significant increase observed in CAT expression following treatment for 3 and $6 \mathrm{~h}(\mathrm{P}<0.05)$. Indeed, as shown in Fig. 4C, the inhibition of $\mathrm{Cx} 43$ translocation to the mitochondria significantly increased Doxo-induced CAT expression at $3 \mathrm{~h}(\mathrm{P}<0.05)$, while no significant differences were observed between the cells treated with Doxo alone and those treated with Doxo and radicicol for $6 \mathrm{~h}$.

ROS are considered to be responsible for the apoptotic effects of Doxo (14). Indeed, if a large amount of $\mathrm{O}_{2}{ }^{-}$is produced within the mitochondria, this cannot pass through 


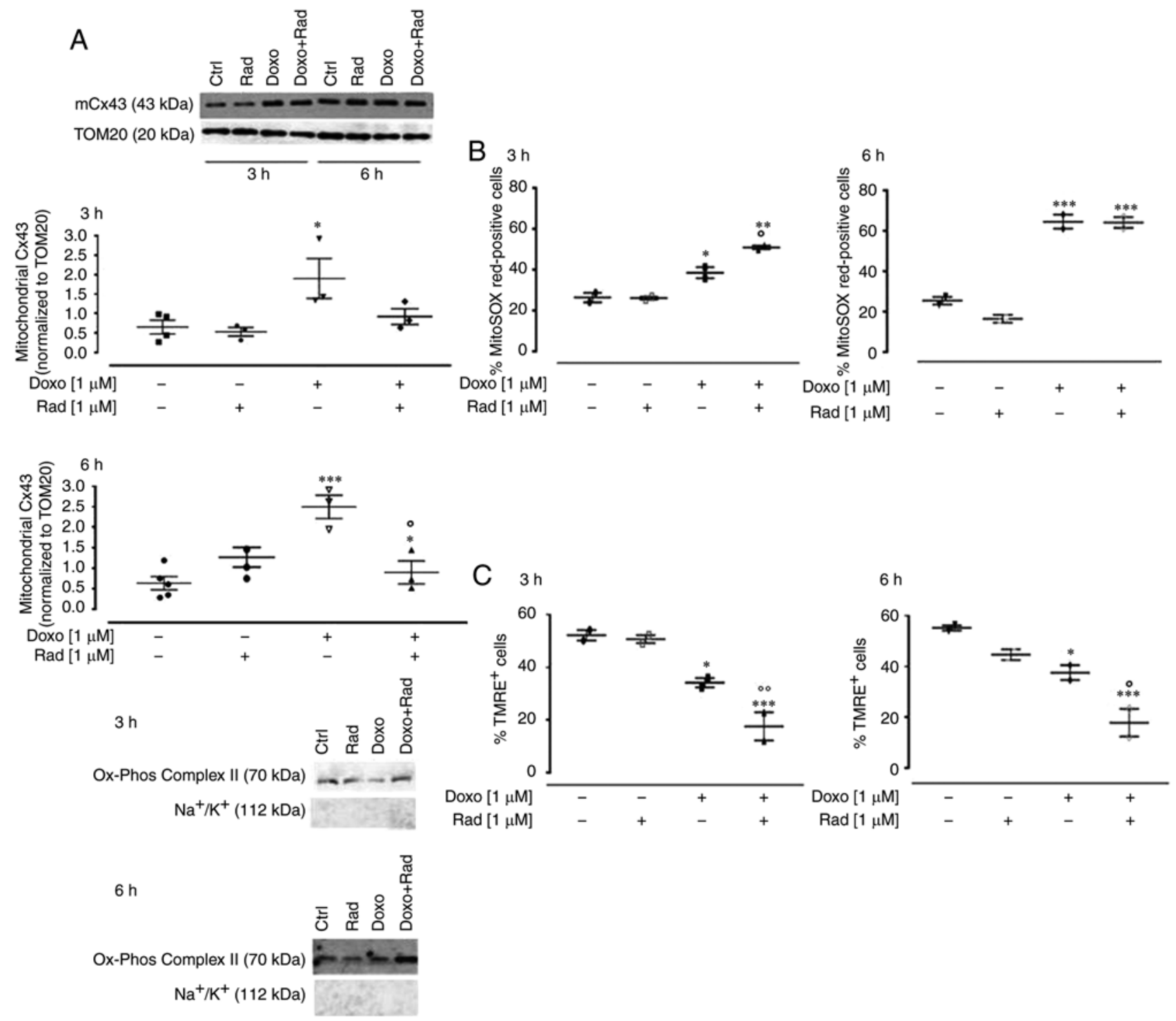

Figure 2. Effects of treatments with Doxo alone and in combination with radicicol on (A) mitochondrial Cx43 expression, (B) mitochondrial ROS production, and (C) mitochondrial membrane potential of $\mathrm{H} 9 \mathrm{c} 2$ cells. Doxo $(1 \mu \mathrm{M})$ was administered for 3 and $6 \mathrm{~h}$, and where indicated, radicicol $(1 \mu \mathrm{M})$ was administered 30 min prior to Doxo. (A) Mitochondrial Cx43 expression was detected by western blot analysis. TOM20 protein expression was used as the loading control. Inset, top panel, representative western blot for $\mathrm{Na}^{+} / \mathrm{K}^{+} \mathrm{ATPase}$ and Ox-phos complex II is shown as markers of mitochondria and sarcolemma, respectively, to demonstrate the purity of the mitochondrial extracts. (B) Mitochondrial superoxide production evaluated using MitoSOX red in the H9c2 cells by flow cytometry, as the percentages of MitoSOX Red-positive cells. (C) Mitochondrial membrane potential was evaluated by flow cytometry analysis with tetramethylrhodamine ethyl ester (TMRE), a cell permeant, positively charged, red-orange dye that penetrates cells and accumulates in the mitochondria in inverse proportion to the membrane potential. A low percentage of TMRE-positive cells indicates that the TMRE dye was not trapped within the mitochondrial membranes, due to its depolarization. Data are the means \pm SEM of fluorescence intensity, from at least 3 independent experiments, each performed in duplicate. ${ }^{*} \mathrm{P}<0.05,{ }^{* *} \mathrm{P}<0.005,{ }^{* * *} \mathrm{P}<0.001$ vs. control; ${ }^{\circ} \mathrm{P}<0.05,{ }^{\circ} \mathrm{P}<0.005$ vs. cells treated with Doxo under the same conditions (one-way ANOVA and multiple comparisons by Bonferroni's test). Doxo, doxorubicin; Rad, radicicol.

the mitochondrial membrane, and can thus damage the mitochondrial DNA (27), which then induces the release of cytochrome $c$ from the mitochondria (28). In the present study, treatment with Doxo induced an increase in the apoptotic response, significantly $(\mathrm{P}<0.005)$ after $6 \mathrm{~h}$ of treatment, as shown by the hyplodiploid nuclei in Fig. 5A. Indeed, it is known that Doxo induces apoptosis through caspase activation via the mitochondrial pathway in cardiomyocytes (29). In the Doxo-treated cells at both treatment times, western blot analysis revealed an increase in caspase 9 expression (Fig. 5B), and a concomitant decrease in procaspase 3 levels (Fig. 5C). The inhibition of $\mathrm{Cx} 43$ translocation to the mitochondria promoted by radicicol enhanced all the pro-apoptotic effects induced by Doxo (Fig. 5).

Inhibition of Cx43 translocation to the mitochondria increases Doxo-induced nitrosative stress. Doxo-derived ROS have been reported to activate the $\mathrm{NF}-\kappa \mathrm{B}$ signaling pathway, which results in an imbalance between the pro-apoptotic and anti-apoptotic proteins (30). NF- $\kappa \mathrm{B}$ is a key orchestrator of inflammation, as it induces expression of the main inflammatory cytokines, adhesion molecules, and NO synthase (31). Usually, the NF- $\kappa \mathrm{B}$ proteins are bound to and inhibited by the $\mathrm{I} \kappa \mathrm{B}$ proteins. Various external stimuli activate the $\mathrm{iKK}$ 

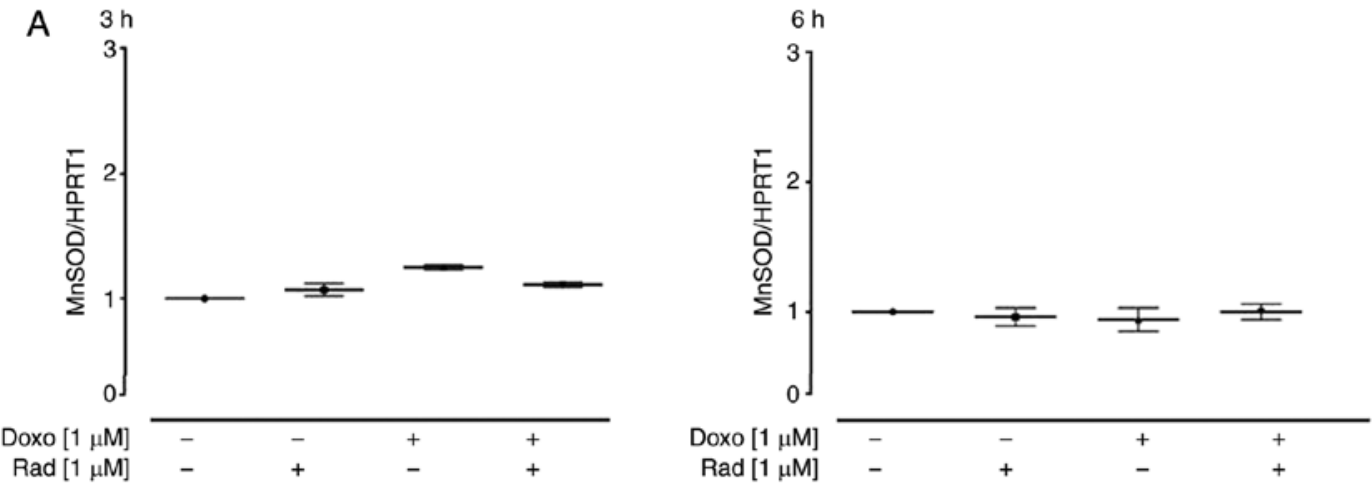

B $3 \mathrm{~h}$

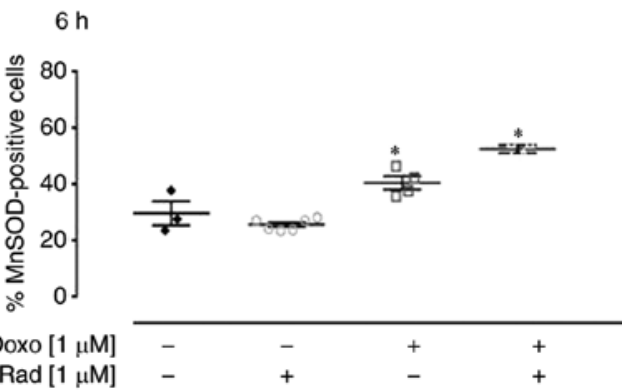

Figure 3. Effects of treatments with Doxo alone and in combination with radicicol on MnSOD (A) gene and (B) protein expression of the H9c2 cells. Doxo $(1 \mu \mathrm{M})$ was administered for 3 and $6 \mathrm{~h}$, and where indicated, radicicol $(1 \mu \mathrm{M})$ was administered 30 min prior to Doxo. (A) MnSOD mRNA levels were evaluated in the H9c2 cells by RT-qPCR, with the data normalized to the HPRT1 gene, The data are presented as the means \pm SD for at least 3 independent experiments, which each performed in triplicate. (B) Superoxide dismutase (MnSOD) levels in the cytosol revealed by flow cytometry of the H9c2 cells. Data are the means \pm SEM for the percentages of MnSOD-positive cells, from at least 3 independent experiments, each performed in duplicate. ${ }^{*} \mathrm{P}<0.05 \mathrm{vs}$. control; (one-way ANOVA and multiple comparisons by Bonferroni's test). Doxo, doxorubicin; Rad, radicicol.

A $3 \mathrm{~h}$

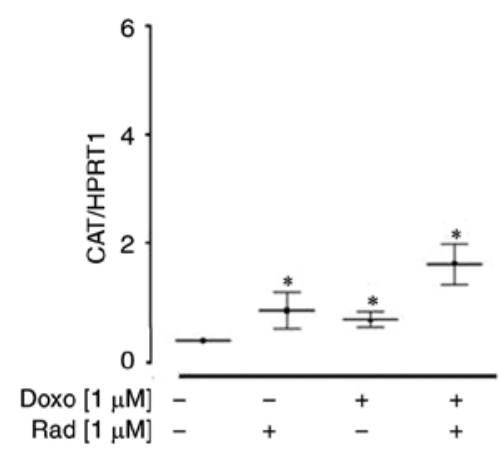

C

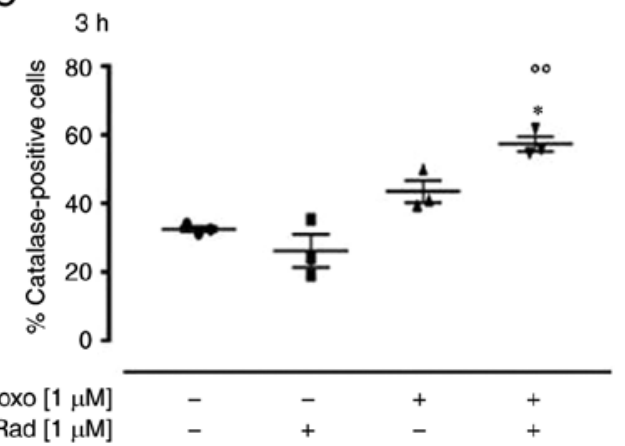

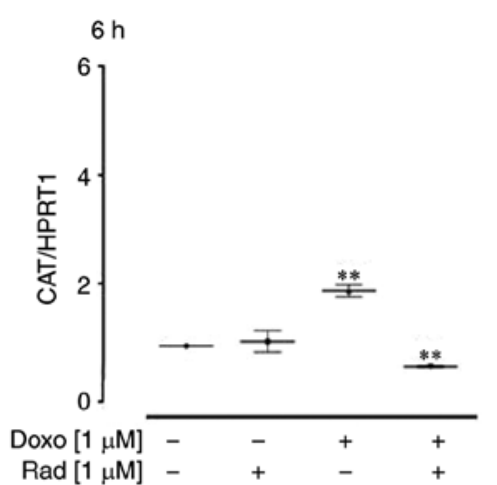

$\mathrm{B}$
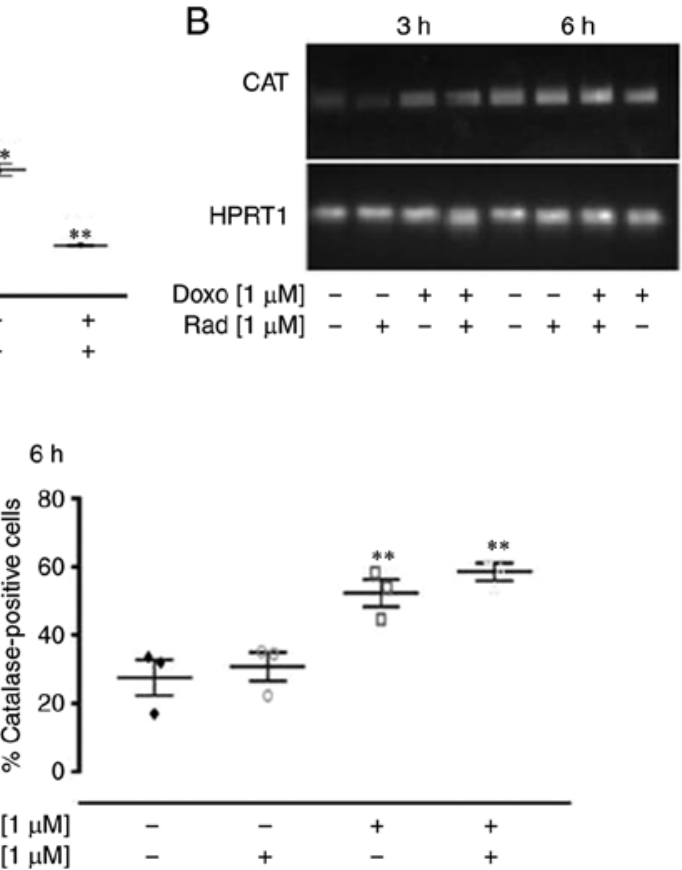

Figure 4. Effects of treatments with Doxo alone and in combination with radicicol on catalase (A and B) gene and (C) protein expression in the H9c2 cells. Doxo $(1 \mu \mathrm{M})$ was administered for 3 and $6 \mathrm{~h}$, and where indicated, radicicol $(1 \mu \mathrm{M})$ was administered 30 min prior to Doxo. (A) CAT mRNA levels analyzed by RT-qPCR, with the data normalized to the HPRT1 gene, The data are presented as the means \pm SD for at least 3 independent experiments, which each performed in triplicate. (B) Representative agarose gel of RT-qPCR products of the data shown in (A). (C) Catalase levels in the cytosol, using flow cytometry for the $\mathrm{H} 9 \mathrm{c} 2$ cells. Data are means \pm SEM for the percentages of catalase-positive cells, from at least 3 independent experiments, each performed in duplicate. ${ }^{*} \mathrm{P}<0.05,{ }^{* *} \mathrm{P}<0.005$ vs. control, ${ }^{\circ} \mathrm{P}<0.005$ vs. cells treated with Doxo under the same conditions (one-way ANOVA and multiple comparisons by Bonferroni's test). Doxo, doxorubicin; Rad, radicicol. 
A $3 \mathrm{~h}$

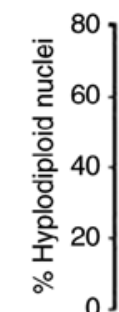

$$
\text { Doxo }[1 \mu \mathrm{M}]
$$
$\operatorname{Rad}[1 \mu \mathrm{M}]$

B
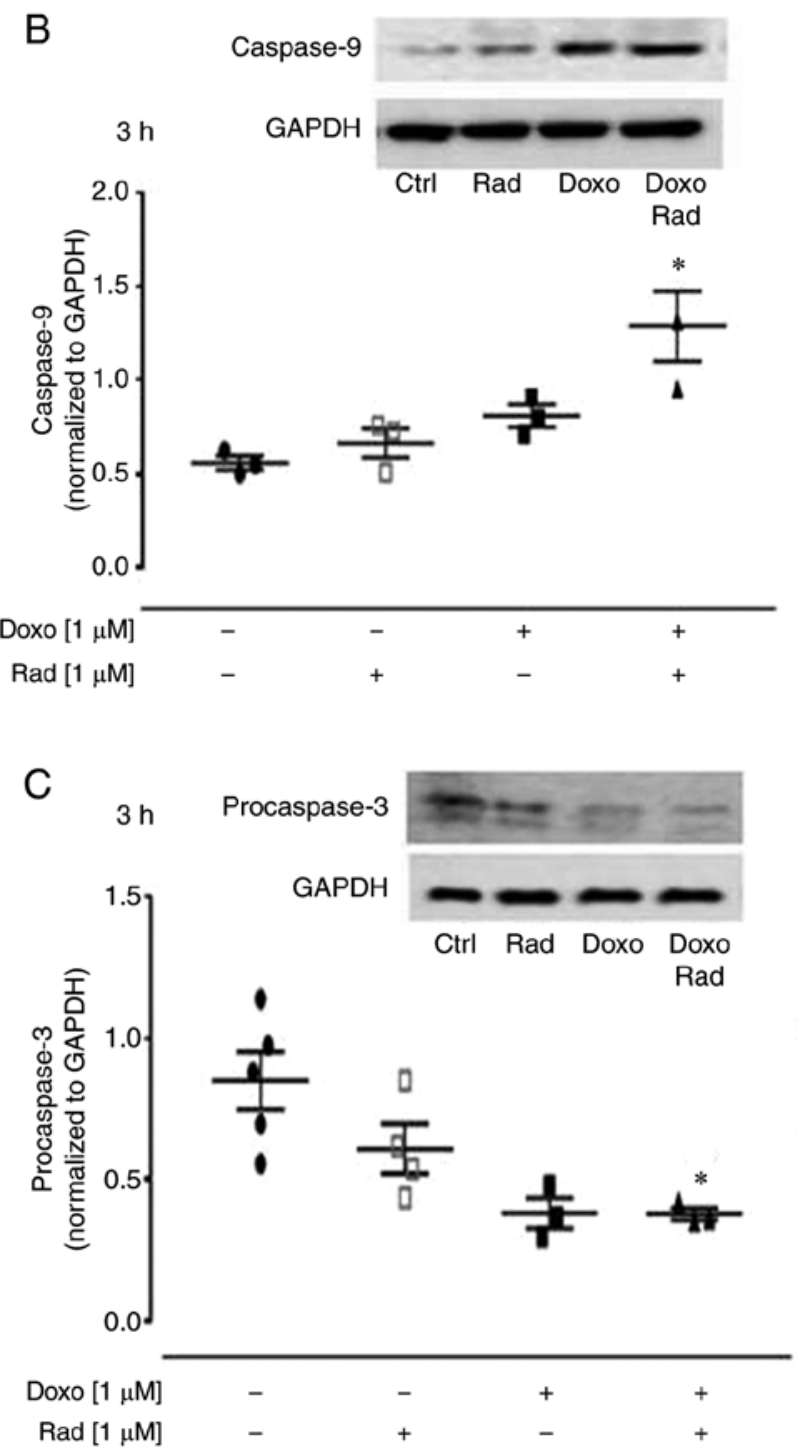
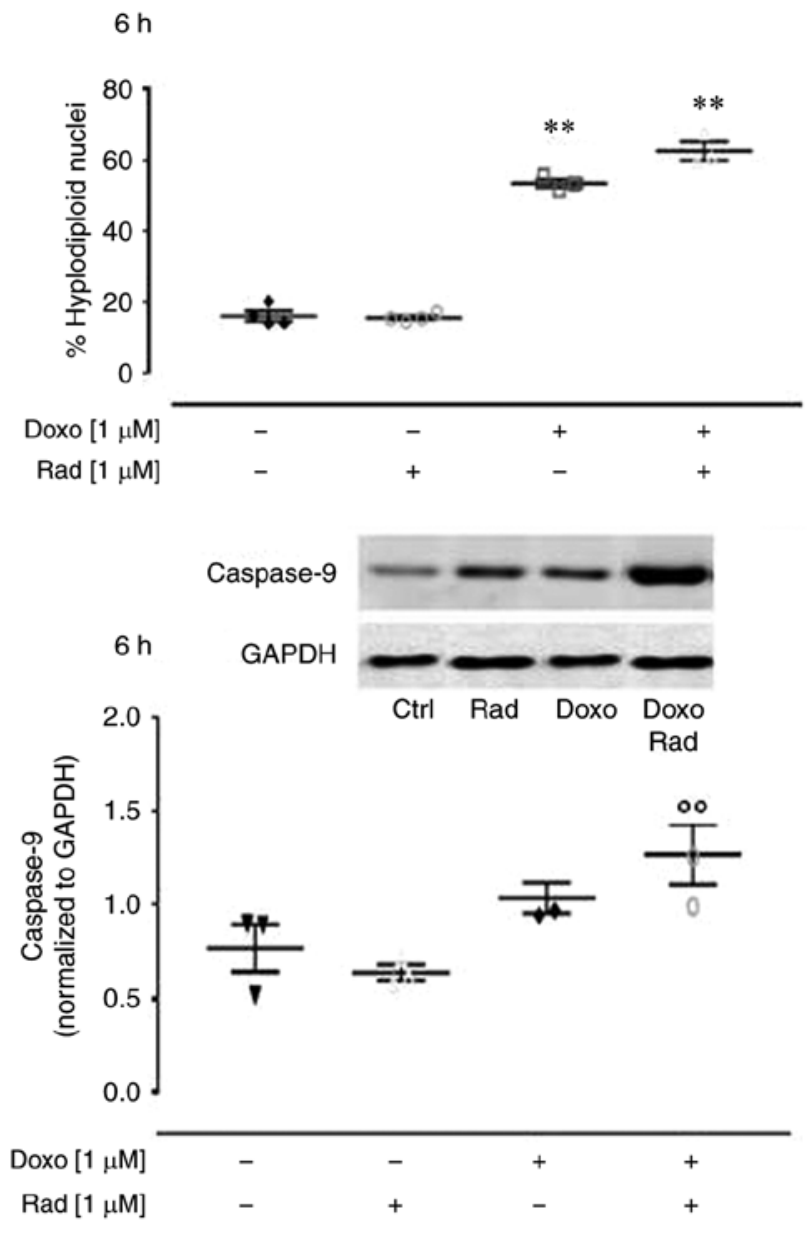

$6 \mathrm{~h}$

Procaspase-3

GAPDH
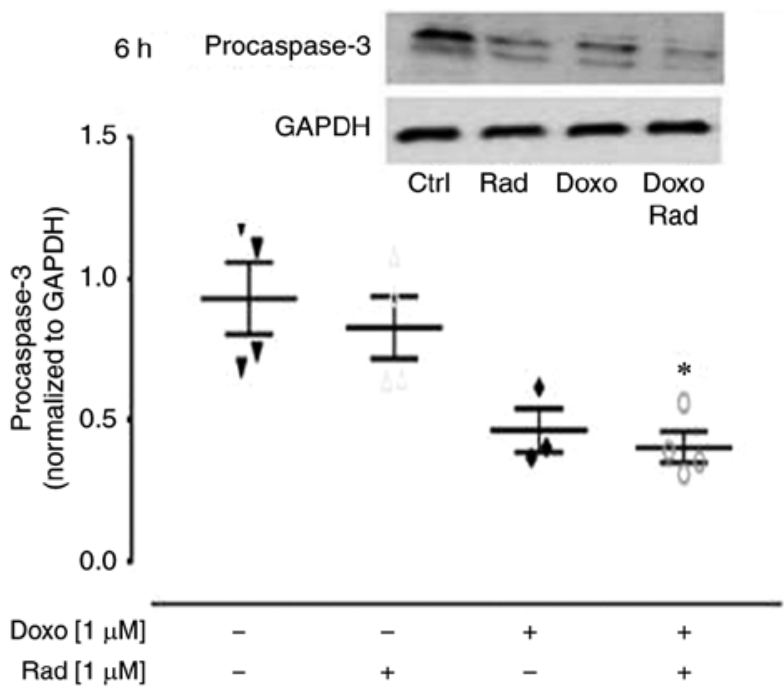

Figure 5. Effects of treatment with Doxo alone and in combination with radicicol on the apoptotic pathway of the H9c2 cells. Doxo $(1 \mu \mathrm{M})$ was administered for 3 and $6 \mathrm{~h}$, and where indicated, radicicol $(1 \mu \mathrm{M})$ was administered $30 \mathrm{~min}$ prior to Doxo. (A) The H9c2 cells were stained by propidium iodide and fluorescence of individual nuclei was measured by flow cytometry. Data are the means \pm SEM for the percentages of hyplodiploid nuclei, from at least 3 independent experiments, each performed in duplicate. (B and C) Caspase 9 (B) and procaspase 3 (C) expression detected by western blot analysis, with Gapdh expression as the loading control. Insets: Representative western blots. Data are the means \pm SEM, from at least 3 independent experiments, each performed in duplicate. ${ }^{*} \mathrm{P}<0.05,{ }^{* *} \mathrm{P}<0.005$, vs. control; ${ }^{\circ} \mathrm{P}<0.05$ and ${ }^{\circ} \mathrm{P}<0.005$ vs. cells treated with Doxo under the same conditions (one-way ANOVA and multiple comparisons by Bonferroni's test). Doxo, doxorubicin; Rad, radicicol.

complex (such as $\mathrm{iKK} \beta, \mathrm{iKK} \alpha$ and NEMO), which phosphorylates the I $\kappa \mathrm{B}$ proteins, and thus free NF- $\kappa \mathrm{B}$ to translocate to the nucleus (32). In the present study, western blot analysis revealed that Doxo treatment significantly enhanced iKK $\alpha$ expression $(\mathrm{P}<0.005$; Fig. $6 \mathrm{~A})$ at $3 \mathrm{~h}$ of treatment, and in agreement with the canonical NF- $\mathrm{KB}$ pathway, there was an increase in the levels of phosphorylated IKB, as detected by flow cytometry (Fig. 6B). The inhibition of $\mathrm{Cx} 43$ translocation 
A

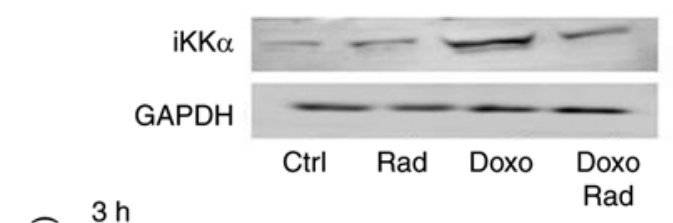

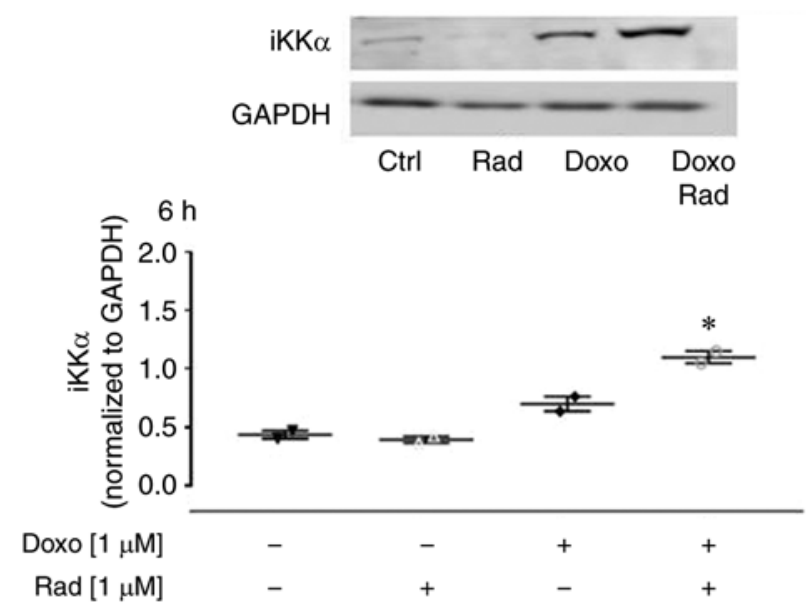

B $3 \mathrm{~h}$
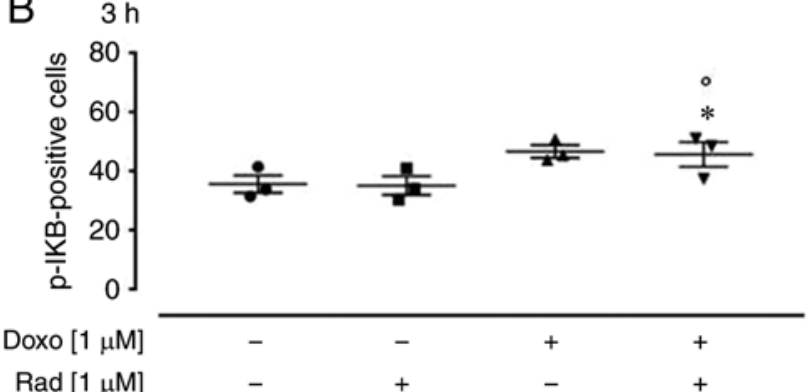

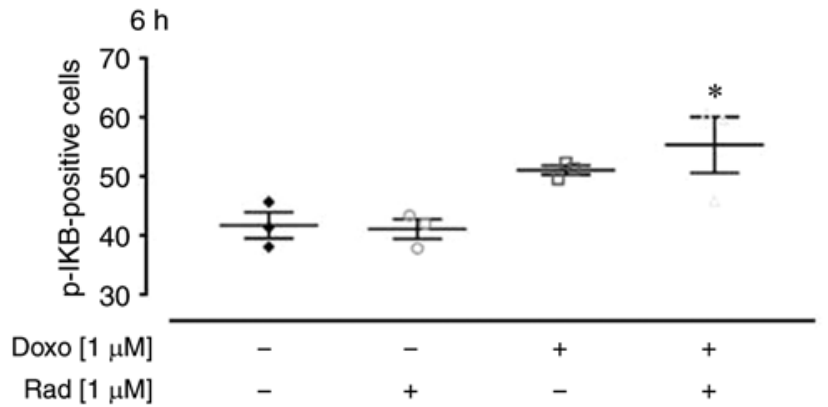

Figure 6. Effects of treatment with Doxo alone and in combination with radicicol on NF- $\mathrm{KB}$ activation of the H9c2 cells. Doxo $(1 \mu \mathrm{M})$ was administered for 3 and $6 \mathrm{~h}$, and where ${ }^{\circ}$ indicated, radicicol $(1 \mu \mathrm{M})$ was administered 30 min prior to Doxo. (A) iKKa expression was examined by western blot analysis, with Gapdh expression as the loading control. Insets: Representative western blots. (B) p-IKB levels using flow cytometry of the H9c2 cells. Data are the means \pm SEM for the percentages of pIKB-positive cells, from at least 3 independent experiments, each performed in duplicate. ${ }^{*} \mathrm{P}<0.05$, ${ }^{* *} \mathrm{P}<0.005$ vs. control; ${ }^{\circ} \mathrm{P}<0.05$ vs. cells treated with Doxo under the same conditions (one-way ANOVA and multiple comparisons by Bonferroni's test). Doxo, doxorubicin; Rad, radicicol.

to the mitochondria activated the $\mathrm{NF}-\kappa \mathrm{B}$ signaling pathway from following $3 \mathrm{~h}$ co-treatment with Doxo (Fig. 6A).

The translocation of NF- $\mathrm{KB}$ to the nucleus induces the transcription of iNOS. Thus, the present study investigated iNOS expression in this experimental model. iNOS is not normally expressed in cardiomyocytes, but it can be activated under intracellular stress conditions. Therefore, due to its generation of free radicals, iNOS represents an indirect marker of intracellular stress. In the present study, indeed, in both the untreated control and Doxo-treated H9c2 cells, there was a low $i N O S$ expression, as shown in Fig. 7A. However, following $6 \mathrm{~h}$ of co-treatment with Doxo plus radicicol, there was a significant increase in $i N O S$ expression $(\mathrm{P}<0.005)$. Western blot analysis revealed that following $6 \mathrm{~h}$ of treatment, there was anincrease in iNOS expression in the Doxo-treated H9c2 cells, and a significant $(\mathrm{P}<0.05)$ increase in the radicicol-pre-treated cells (Fig. 7B). The quantitative protein analysis of iNOS by western blot analysis confirmed the data from RT-qPCR.

Nitrite release represents an indirect indicator of NO production, and this was measured in the medium of the $\mathrm{H} 9 \mathrm{c} 2$ cells to determine the enzymatic activity of iNOS. However, the nitrite levels were not quantifiable under the current experimental conditions (data not shown). As NO rapidly reacts in the presence of high $\mathrm{O}_{2}^{-}$levels to form peroxynitrite, which can then induce nitration of the aromatic side-chains of tyrosine in proteins, the levels of nitrotyrosine were investigated in the $\mathrm{H} 9 \mathrm{c} 2$ cells treated as described above. Fig. 7C illustrates the data from the cytofluorimetric analysis that revealed an increase in nitrotyrosine levels in the Doxo-treated H9c2 cells. Indeed, the inhibition of $\mathrm{Cx} 43$ translocation to the mitochondria significantly $(\mathrm{P}<0.005)$ enhanced the nitrotyrosine levels following $6 \mathrm{~h}$ of treatment.

Finally, to determine the contribution of iNOS and its products to Doxo-induced apoptosis, L-NAME, a specific iNOS inhibitor, was used (33). The data obtained by FACS indicated that L-NAME significantly decreased Doxo-induced apoptosis $(\mathrm{P}<0.05)$ after $3 \mathrm{~h}$ of treatment. The inhibition of $\mathrm{Cx} 43$ translocation to the mitochondria reduced the protective effects of L-NAME on Doxo-induced apoptosis, particularly after $6 \mathrm{~h}$ of treatment (Fig. 7D).

\section{Discussion}

The survival of cancer patients has significantly increased over the past 20 years. However, to obtain these benefits, a large price has to be paid in terms of the side-effects associated with the use of intensive anticancer treatments. In particular, chronic cardiotoxicity can compromise the clinical efficacy of chemotherapies, which will affect the survival and quality of the life of patients, regardless of the oncological prognosis. Indeed, cardiotoxicity is the main limitation to the clinical use of Doxo. The proposed mechanisms for Doxo-induced 
A $\quad 3 \mathrm{~h}$

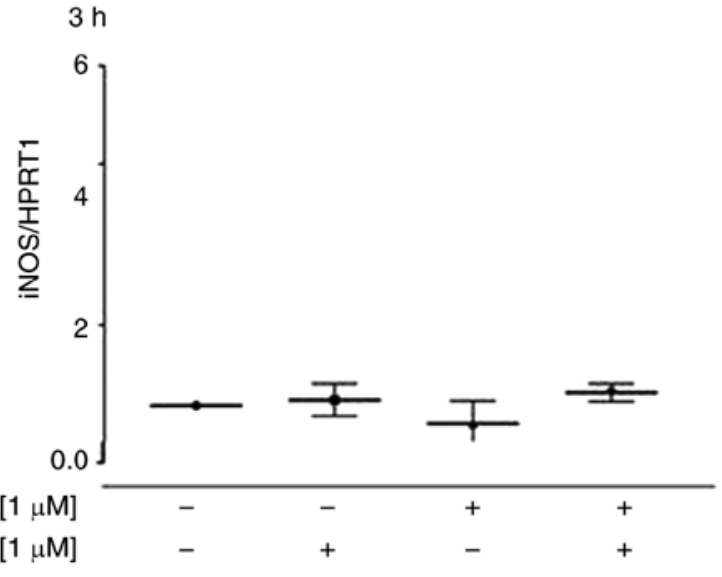

B

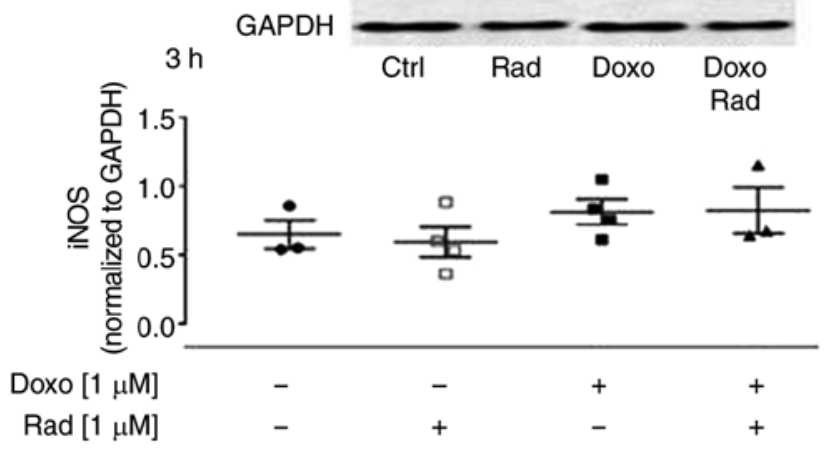

C

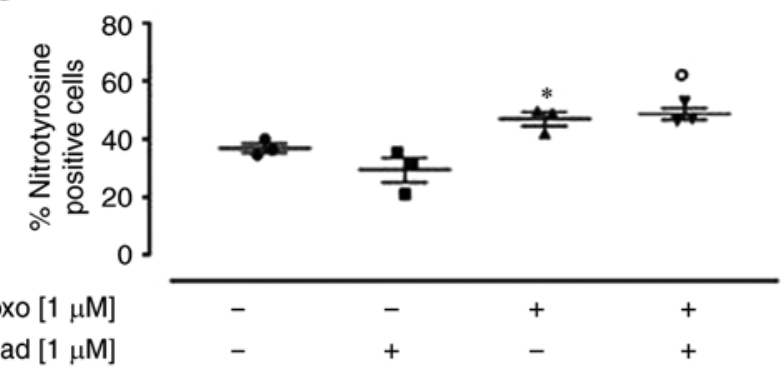

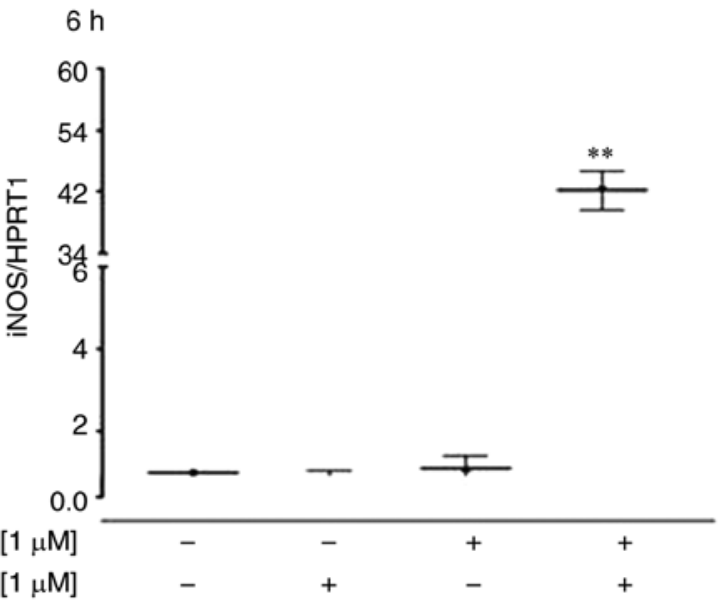

$\operatorname{Rad}[1 \mu \mathrm{M}]$
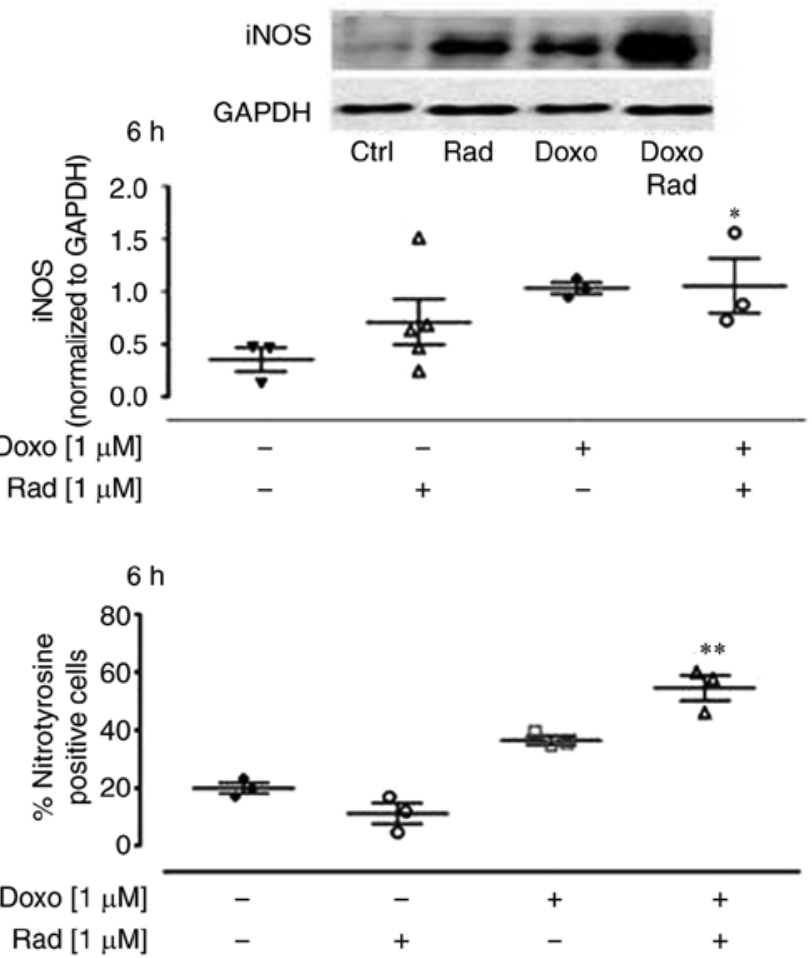

D

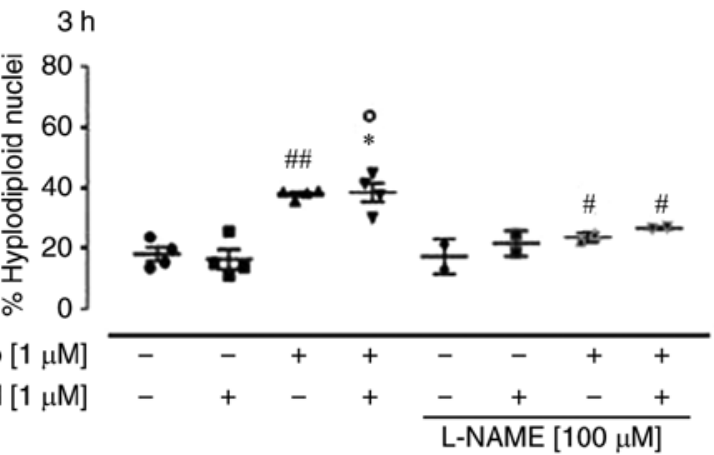

$6 \mathrm{~h}$

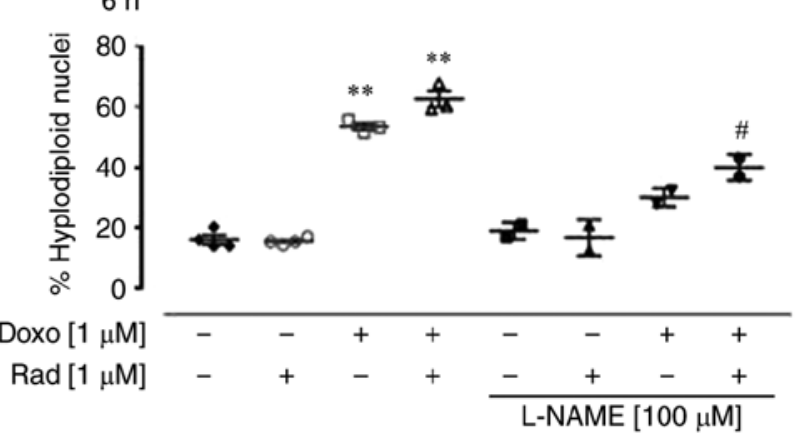

Figure 7. Effects of treatment with Doxo alone and in combination with radicicol on iNOS (A) gene and (B) protein expression, and (C) nitrotyrosine formation, and with the (D) addition of L-NAME for apoptosis, of the H9c2 cells. Doxo $(1 \mu \mathrm{M})$ was administered for 3 or $6 \mathrm{~h}$, and where indicated, radicicol $(1 \mu \mathrm{M})$ was administered 30 min prior to Doxo. (A) iNOS mRNA levels analyzed by RT-qPCR, with the data normalized to the HPRT1 gene The data are presented as the means \pm SD for at least 3 independent experiments, which each performed in triplicate. (B) iNOS expression was detected by western blot analysis, with Gapdh expression as the loading control. Insets: Representative western blots. (C) Nitrotyrosine levels using flow cytometry of the H9c2 cells. Data are the means \pm SEM for the percentages of nitrotyrosine-positive cells, from at least 3 independent experiments, each performed in duplicate. (D) Effects of L-NAME on apoptosis induced under the same conditions. Data are the means \pm SEM for the percentages of hypodiploid nuclei, from at least 3 independent experiments, each performed in duplicate. ${ }^{*} \mathrm{P}<0.05,{ }^{* *} \mathrm{P}<0.005$, vs. control; ${ }^{\circ} \mathrm{P}<0.05$ vs. cells treated with Doxo under the same experimental conditions; and ${ }^{\#} \mathrm{P}<0.05$ and ${ }^{\# \#} \mathrm{P}<0.005$, for cells co-treated with Doxo and L-NAME vs. Doxo (one-way ANOVA and multiple comparisons by Bonferroni's test). Doxo, doxorubicin; Rad, radicicol. 
cardiotoxicity are complex, and they involve increased oxidative/nitrosative stress and the activation of downstream effector pathways (15). As the involvement of $\mathrm{Cx} 43$ in Doxo-induced mitochondrial dysfunction and oxidative stress was recently demonstrated (9), the present study was designed to determine whether mitochondrial $\mathrm{Cx} 43$ is also involved in Doxo-induced nitrosative stress. For this purpose, H9c2 cells were treated with $1 \mu \mathrm{M}$ Doxo for 3 and $6 \mathrm{~h}$, in both the absence and presence of radicicol, an Hsp90 inhibitor. Indeed, although it is well known that Hsp90 is involved in a number of other cellular processes (22), radicicol is widely used as a pharmacological tool to block the Doxo-induced translocation of $\mathrm{Cx} 43$ to the mitochondria $(4,9)$, just as another Hsp90 inhibitor has been used to study the role of mitochondrial Cx43 in cardioprotection (35).

In a previous study, the authors reported data obtained by FACS on the effects of Doxo on mitochondrial ROS production and on mitochondrial membrane depolarization (10). These data were repeated in the present study as part of the background to the present the investigation (as shown in Fig. 2), to confirm that the experimental conditions were suitable to reproduce the cardiotoxic effects of Doxo and its consequences on mitochondrial $\mathrm{Cx} 43$ expression. The deleterious effects of Doxo on the H9c2 cells treated for 3 and $6 \mathrm{~h}$ were also confirmed using Toluidine blue staining. The morphological variations observed following these treatments are in agreement with those of another study that described atypical and wrinkled aspects of the nuclei of the damaged cells (34). Once the increase in intracellular ROS was confirmed herein through MitoSox and TMRE analyses, the various antioxidant systems that were activated in response to this were investigated. Two antioxidant enzymes were evaluated: MnSOD and CAT, which are known to cooperate in the defense mechanisms against free radicals. Interesting data emerged herein regarding these two enzymes. The expression of $M n S O D$ was shown to increase following treatment with Doxo for $3 \mathrm{~h}$, which represents the nuclear response that was aimed at intensifying the production of MnSOD, to reduce the high ROS concentrations detected by the intracellular sensing systems. Conversely, following $6 \mathrm{~h}$ of Doxo treatment, no changes in $M n S O D$ expression were observed. CAT expression analysis revealed a similar trend. Indeed, after $3 \mathrm{~h}$ of Doxo treatment, the expression of $C A T$ was enhanced, with an evident additive effect observed with co-treatment with radicicol, while at $6 \mathrm{~h}$ of Doxo treatment, it was also diminished. However, the data obtained by FACS demonstrated that the expression of both the MnSOD and CAT proteins remained high, even in the cells treated with Doxo for $6 \mathrm{~h}$.

The apparent contrast between the data obtained by FACS on the expression of these enzymes, where there was a time-dependent increase in MnSOD, with the data obtained by RT-qPCR, can be explained by consideration that the cellular concentrations of proteins usually correlate with the abundances of their corresponding mRNAs, although not necessarily strongly. Further data addressing this issue indicate that in almost every organism, the transcript abundance only partially predicts the protein levels, which suggests that other modes of regulation need to be invoked to explain how proteins levels are indeed set within cells (37).

Moreover, as Vogel and Marcotte previously reported (36), in mammalian cells, mRNAs are produced at much lower rates than the proteins are; similarly, the mRNAs are less stable than the proteins. This condition may be complicated by the post-transcriptional mechanisms involved in turning mRNAs into proteins. In addition, the data of the present study can be explained by the activation of programmed cell death, which was strongly initiated following $6 \mathrm{~h}$ of Doxo treatment, compared with $3 \mathrm{~h}$. Indeed, the activation of the apoptotic pathway would inhibit the nuclear response in terms of the modulation of gene expression, by shifting the cellular energies towards the activation of these 'controlled' death mechanisms, hence reducing mRNA production.

It is well known that Doxo also induces the NF- $\kappa \mathrm{B}$ signaling pathway (37). The data of the present study demonstrated that Doxo induced an increase in $\mathrm{iKK} \alpha$ and p-IKB expression, thus indicating the activation of NF- $\kappa B$ in the current experimental model. This activation of NF- $\mathrm{KB}$ results in an increase in iNOS gene and protein expression. Nitrite and nitrate release into the medium of these treated $\mathrm{H} 9 \mathrm{c} 2$ cells as indicators of NO production was not evaluable herein, although elevated levels of nitrotyrosine were shown. Indeed, in agreement with previous reports, it was found that the NO produced by iNOS will rapidly react with $\mathrm{H}_{2} \mathrm{O}_{2}$ or $\mathrm{O}_{2}-$ generated by the mitochondria, to form the highly reactive and harmful peroxynitrite $(21,38)$, which then finally induces nitrotyrosine formation $(28,39)$. Furthermore, and for the first time, to the best of our knowledge, it was demonstrated herein that the inhibition of $\mathrm{Cx} 43$ translocation to the mitochondria, and the consequent increase in mitochondrial superoxide release, significantly increases the deleterious effects of Doxo-induced iNOS overexpression. Indeed, the inhibition of iNOS alone in the presence of L-NAME did not completely block Doxo-induced apoptosis.

In conclusion, the present study supports the concept that Doxo induces both oxidative and nitrosative stress, and that these are closely related to each other. However, the present study we focused mainly on the role of the mitochondria. It was hypothesized that mitochondrial damage appears at an earlier stage, as indicated by the compensatory mechanisms implemented by the cells (e.g., mitoCx43 overexpression, increased $M n S O D$ and $C A T$ gene expression). However, if the increase in mitochondrial ROS production cannot be counteracted, this will also amplify the damage produced by activation of the NF- $\kappa B$-mediated pathway. This is in agreement with the findings of previous studies that have reported that mitochondrial superoxide generation occurs within minutes of Doxo administration, whereas cell death becomes evident only at a later stage, when significant amounts of peroxynitrite have been generated (15). Indeed, the present study demonstrated that the mechanisms that further increase the mitochondrial superoxide generation (e.g., the inhibition of $\mathrm{Cx} 43$ translocation to the mitochondria) can significantly accelerate the occurrence of cell death.

Further studies are scheduled to determine whether the oxidative stress observed in cells in which $\mathrm{Cx} 43$ translocation to the mitochondria is blocked can be rescued using antioxidants, as the protective effects of antioxidants against Doxo-induced toxicity have been reported (40).

\section{Acknowledgements}

Not applicable. 


\section{Funding}

The present study was supported by the University of Salerno, through a FARB 2018 grant to APo.

\section{Availability of data and materials}

All data used during the current study are available from the corresponding author on reasonable request.

\section{Authors' contributions}

APo and GM conceived and designed the experiments. MP, BP and MCDM performed the experiments. MCDM and SM analyzed the data and revised the manuscript. APi and RM conceived the experiments and revised the manuscript. MP, APo and GM wrote the manuscript. All authors have read and approved the final manuscript.

\section{Ethics approval and consent to participate}

Not applicable.

\section{Patient consent for publication}

Not applicable.

\section{Competing interests}

The authors declare that they have no competing interests.

\section{References}

1. Michela P, Velia V, Aldo P and Ada P: Role of connexin43 in cardiovascular diseases. Eur J Pharmacol 768: 71-76, 2015.

2. Severs NJ, Bruce AF, Dupont E and Rothery S: Remodelling of gap junctions and connexin expression in diseased myocardium. Cardiovasc Res 80: 9-19, 2008.

3. Fontes MS, van Veen TA, de Bakker JM and van Rijen HV: Functional consequences of abnormal $\mathrm{Cx} 43$ expression in the heart. Biochim Biophys Acta 1818: 2020-2029, 2012.

4. Ruiz-Meana M, Rodríguez-Sinovas A, Cabestrero A, Boengler K, Heusch G and Garcia-Dorado D: Mitochondrial connexin43 as a new player in the pathophysiology of myocardial ischaemia-reperfusion injury. Cardiovasc Res 77: 325.333, 2008.

5. Boengler K, Stahlhofen S, van de Sand A, Gres P, Ruiz-Meana M, Garcia-Dorado D, Heusch G and Schulz R: Presence of connexin 43 in subsarcolemmal, but not in interfibrillar cardiomyocyte mitochondria. Basic Res Cardiol 104: 141-147, 2009.

6. Heinzel FR, Luo Y, Li X, Boengler K, Buechert A, García-Dorado D, Di Lisa F, Schulz R and Heusch G: Impairment of diazoxide-induced formation of reactive oxygen species and loss of cardioprotection in connexin 43 deficient mice. Circ Res 97: 583-586, 2005.

7. Rehling P, Brandner K and Pfanner N: Mitochondrial import and the twin-pore translocase. Nat Rev Mol Cell Biol 5: 519-530, 2004.

8. Lu G,HaiderHKh,Porollo A and AshrafM: Mitochondria-specific transgenic overexpression of connexin- 43 simulates preconditioning-induced cytoprotection of stem cells. Cardiovasc Res 88 277-286, 2010

9. Pecoraro M, Sorrentino R, Franceschelli S, Del Pizzo M, Pinto A and Popolo A: Doxorubicin-mediated cardiotoxicity: Role of mitochondrial connexin 43. Cardiovasc Toxicol 15: 366-376, 2015.

10. Pecoraro M, Ciccarelli M, Fiordelisi A, Iaccarino G, Pinto A and Popolo A: Diazoxide improves mitochondrial connexin 43 expression in a mouse model of doxorubicin-induced cardiotoxicity. Int J Mol Sci 19: 757, 2018.
11. Kondru SK, Potnuri AG, Allakonda L and Konduri P: Histamine 2 receptor antagonism elicits protection against doxorubicin-induced cardiotoxicity in rodent model. Mol Cell Biochem 441: 77-88, 2018.

12. Octavia Y, Tocchetti CG, Gabrielson KL, Janssens S, Crijns HJ and Moens AL: Doxorubicin-induced cardiomyopathy: From molecular mechanisms to therapeutic strategies. J Mol Cell Cardiol 52: 1213-1225, 2012.

13. Berthiaume JM and Wallace KB: Persistent alterations to the gene expression profile of the heart subsequent to chronic doxorubicin treatment. Cardiovasc Toxicol 7: 178-191, 2007.

14. Angsutararux $\mathrm{P}$, Luanpitpong $\mathrm{S}$ and Issaragrisil S: Chemotherapy-induced cardiotoxicity: Overview of the roles of oxidative stress. Oxid Med Cell Longev 2015: 795602, 2015.

15. Mukhopadhyay P, Rajesh M, Bátkai S, Kashiwaya Y, Haskó G, Liaudet L, Szabó C, Pacher P and Am J: Role of superoxide nitric oxide and peroxynitrite in doxorubicin-induced cell death in vivo and in vitro. Physiol Heart Circ Physiol 296: H1466-H1483, 2009.

16. Pacher P, Beckman JS and Liaudet L: Nitric oxide and peroxynitrite in health and disease. Physiol Rev 87: 315-424, 2007.

17. Tsutsui H, Kinugawa $S$ and Matsushima S: Oxidative stress and heart failure. Am J Physiol Heart Circ Physiol 301: H2181-H2190, 2011.

18. Xu Z, Lin S, Wu W, Tan H, Wang Z, Cheng C, Lu L and Zhang X: Ghrelin prevents doxorubicin-induced cardiotoxicity through TNF-alpha/NF-kappaB pathways and mitochondrial protective mechanisms. Toxicology 247: 133-138, 2008.

19. Shirazi LF Bissett J, Romeo F and Jawahar LM: Role of Inflammation in heart failure. Curr Atheroscl Rep 19: 27, 2017.

20. Bartekova M, Radosinska J, Jelemensky M and Dhalla NS: Role of cytokines and inflammation in heart function during health and disease. Heart Failure Rev 23: 733-758, 2018.

21. Sanskriti K, Gurinder BS and Madhu K: Nitric oxide synthase and diabetic cardiomyopathy. Nitric Oxide 43: 29-34, 2014.

22. Schulte TW, Akinaga S, Soga S, Sullivan W, Stensgard B, Toft D and Neckers LM: Antibiotic radicicol binds to the N-terminal domain of Hsp90 and shares important biologic activities with geldanamycin. Cell Stress Chaper 3: 100-108, 1998.

23. Livak KJ and Schmittgen TD: Analysis of relative gene expression data using real-time quantitative PCR and the 2(-Delta Delta C(T)) method. Methods 25: 402-408, 2001.

24. Boengler K, Dodoni G, Rodriguez-Sinovas A, Cabestrero A, Ruiz-Meana M, Gres P, Konietzka I, Lopez-Iglesias C, Garcia-Dorado D, Di Lisa F, et al: Connexin 43 in cardiomyocyte mitochondria and its increase by ischemic preconditioning. Cardiovasc Res 67: 234-244, 2005.

25. Di Iorio B, Marzocco S, Di Micco L, Adesso S, De Blasio A, Autore G, Sirico ML, Fazeli G and Heidland A: High-tone external muscle stimulation in patients with acute kidney injury (AKI): Beneficial effects on NO metabolism asymmetric dimethylarginine and endothelin-1. Clin Nephrol 82: 304-312, 2014.

26. Miao L and St Clair DK: Regulation of superoxide dismutase genes: Implications in disease. Free Radic Biol Med 47: 344-356, 2009.

27. Wallace DC: Mitochondrial defects in cardiomyopathy and neuromuscular disease. Am Heart J 139: S70-S85, 2000.

28. Pecoraro M, Del Pizzo M, Marzocco S, Sorrentino R, Ciccarelli M, Iaccarino G, Pinto A and Popolo A: Inflammatory mediators in a short-time mouse model of doxorubicin-induced cardiotoxicity. Toxicol Appl Pharmacol 293: 44-52, 2016.

29. Ueno M, Kakinuma Y, Yuhki K, Murakoshi N, Iemitsu M, Miyauchi T and Yamaguchi I: Doxorubicin induces apoptosis by activation of caspase-3 in cultured cardiomyocytes in Vitro and rat cardiac ventricles in Vivo. J Pharmacol Sci 101: 151-158, 2006.

30. Ghosh J, Das J, Manna P and Sil PC: The protective role of arjunolic acid against doxorubicin induced intracellular ROS dependent JNK-p38 and p53-mediated cardiac apoptosis. Biomaterials 32: 4857-4866, 2011.

31. Del Prete A, Allavena P, Santoro G Fumarulo R, Corsi MM and Mantovani A: Molecular pathways in cancer-related inflammation. Biochem Med (Zagreb) 21: 264-275, 2011.

32. Perkins ND: Post-translational modifications regulating the activity and function of the nuclear factor $\kappa \mathrm{B}$ pathway. Oncogene 25: 6717-6730, 2006.

33. Marzocco S, Adesso S, Alilou M, Stuppner H and Schwaiger S: Anti-inflammatory and anti-oxidant potential of the root extract and constituents of doronicum austriacum. Molecules 22: 1003, 2017. 
34. Witek P, Korga A, Burdan F, Ostrowska M, Nosowska B, Iwan M and Dudka J: The effect of a number of H9C2 rat cardiomyocytes passage on repeatability of cytotoxicity study results. Cytotechnology 68: 2407-2415, 2016.

35. Tu RH, Li QJ, Huang Z, He Y, Meng JJ, Zheng HL, Zeng ZY and Zhong GQ: Novel functional role of heat shock protein 90 in mitochondrial connexin 43-mediated hypoxic postconditioning. Cell Physiol Biochem 44: 982-997, 2017.

36. Vogel C and Marcotte EM: Insights into the regulation of protein abundance from proteomic and transcriptomic analyses. Nat Rev Genet 13: 2227-2232, 2012.

37. Wang J, Ma L, Tang X, Zhang X, Qiao Y, Shi Y, Xu Y, Wang Z, $\mathrm{Yu}$ Y and Sun F: Doxorubicin induces apoptosis by targeting Madcam1 and AKT and inhibiting protein translation initiation in hepatocellular carcinoma cells. Oncotarget 6: 24075-24091, 2015.
38. Balligand JL and Cannon PJ: Nitric oxide synthases and cardiac muscle. Autocrine and paracrine influences. Arterioscler Thromb Vasc Biol 17: 1846-1858, 1997.

39. Ahsan H: 3-Nitrotyrosine: A biomarker of nitrogen free radical species modified proteins in systemic autoimmunogenic conditions. Hum Immunol 74: 1392-1399, 2013.

40. Ye M, Zhang L, Yan Y and Lin H: Punicalagin protects H9c2 cardiomyocytes from doxorubicin-induced toxicity through activation of Nrf2/HO-1 signaling. Biosci Rep 39: BSR20190229, 2019.

(i) (9) This work is licensed under a Creative Commons Attribution-NonCommercial-NoDerivatives 4.0 International (CC BY-NC-ND 4.0) License. 